San Jose State University

SJSU ScholarWorks

Master's Theses

Master's Theses and Graduate Research

1989

\title{
A comparison of an affective level of programmed instruction with traditional classroom instruction to achieve a clinical competency in staff nurses
}

Laurie Laverty

San Jose State University

Follow this and additional works at: https://scholarworks.sjsu.edu/etd_theses

\section{Recommended Citation}

Laverty, Laurie, "A comparison of an affective level of programmed instruction with traditional classroom instruction to achieve a clinical competency in staff nurses" (1989). Master's Theses. 3154.

DOI: https://doi.org/10.31979/etd.nmcn-zhj6

https://scholarworks.sjsu.edu/etd_theses/3154

This Thesis is brought to you for free and open access by the Master's Theses and Graduate Research at SJSU ScholarWorks. It has been accepted for inclusion in Master's Theses by an authorized administrator of SJSU ScholarWorks. For more information, please contact scholarworks@sjsu.edu. 


\section{INFORMATION TO USERS}

The most advanced technology has been used to photograph and reproduce this manuscript from the microfilm master. UMI films the text directly from the original or copy submitted. Thus, some thesis and dissertation copies are in typewriter face, while others may be from any type of computer printer.

The quality of this reproduction is dependent upon the quality of the copy submitted. Broken or indistinct print, colored or poor quality illustrations and photographs, print bleedthrough, substandard margins, and improper alignment can adversely affect reproduction.

In the unlikely event that the author did not sent UMI a complete manuscript and there are missing pages, these will be noted. Also, if unauthorized copyright material had to be removed, a note will indicate the deletion.

Oversize materials (e.g., maps, drawings, charts) are reproduced by sectioning the original, beginning at the upper left-hand corner and continuing from left to right in photographed in one exposure and is included in reduced form at the back of the book.

Photographs included in the original manuscript have been reproduced xerographically in this copy. Higher quality $6 "$ " 9 " black and white photographic prints are available for any photographs or illustrations appearing in this copy for an additional charge. Contact UMI directly to order. 
Order Number 1338707

A comparison of an affective level of programmed instruction with traditional classroom instruction to achieve a clinical competency in staff nurses

Laverty, Laurie Hodgson, M.S.

San Jose State University, 1989

$\mathrm{U} \cdot \mathrm{M} \cdot \mathrm{I}$

300 N. Zeeb Rd.

Ann Arbor, MI 48106 
- 


\title{
A COMPARISON OF AN AFFECTIVE LEVEL OF PROGRAMMED INSTRUCTION WITH TRADITIONAL CLASSROOM INSTRUCTION TO ACHIEVE A CLINICAL COMPETENCY IN STAFF NURSES
}

\author{
A Thesis \\ Presented to \\ the Faculty of the Departinent of firusing \\ San Jose State University
}

\author{
In Partial Fulifillment \\ of the Requirement for the Degree \\ Master of Science
}

by

Laurie Laverty

August 1989 
APPROVED FOR THE DEPARTMENT OF NURSING

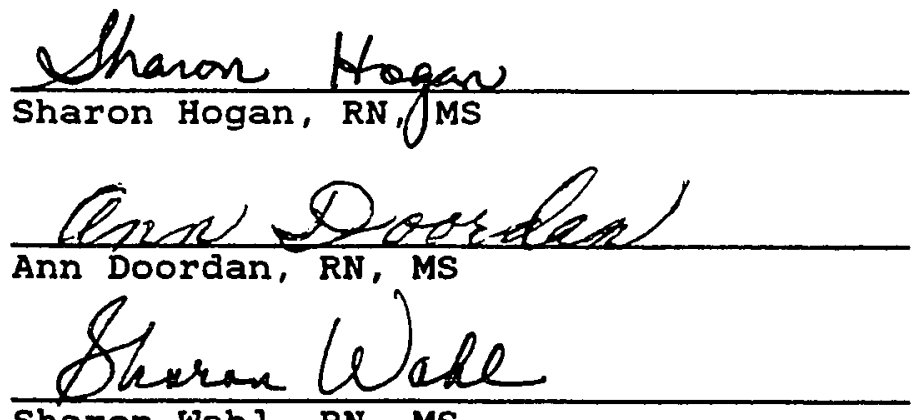
Sharon Wahl, RN, MS

APPROVED FOR THE UNIVERSITY

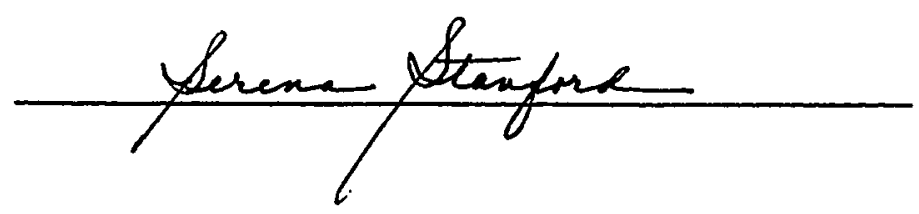




\section{ACKNOWLEDGMENTS}

There have been several people who have provided me with critical support during the past two years. I wish to extend a sincere appreciation to all those involved.

To my husband Rob, who through two years of graduate school provided me with the support and encouragement to achieve my educational goals. Without his help (sometimes at 2:00 AM) in teaching me how to use the computer printer and his willingness to take on many extra domestic chores, this thesis could not have been completed.

To Sharon Hogan, my first reader, of the nursing faculty of San Jose State University, who made it possible for me to continue working on my original thesis through the transition from one university to another, and who devoted many hours searching throughout this thesis for the hyphenated word "posttest."

To Ann Doordan and Sharon Whal, of the nursing faculty of San Jose State University, who spent many hours reading and re-reading this thesis and providing valuable suggestions for improvement. 


\section{ABSTRACT}

A COMPARISON OF AN AFFECTIVE LEVEL OF PROGRAMMED INSTRUCTION WITH CLASSROOM INSTRUCTION TO ACHIEVE A CLINICAL COMPETENCY IN STAFE NURSES

by: Laurie Laverty

This study used a comparative design to demonstrate the effectiveness of two different methods of instruction on affective skill mastery. The sample for this study were newly employed critical care nurses. Instruction was provided by (a) traditional classroom instruction and by (b) self Instruction. Both groups were pretested and posttested using the same instrument. Data were collected using a 23 item test which consisted of fifteen multiple choice Items and eight attitudinal statements which were rated on a likert scale.

Analysis of the pretests and posttests for both groups showed significant statistical differences at the .05 level. The self-instruction group showed greater improvement, ( $P=$ $.0001)$ than did the classroom instruction group $(p=.003)$. There was no statistically significant difference between the posttests of both groups on the $t$ test. Although the present study had a small sample size, the findings indicate that affective content may be successfully taught to nurses in the setting of classroom instruction or self-instruction. 
TABLE OF CONTENTS

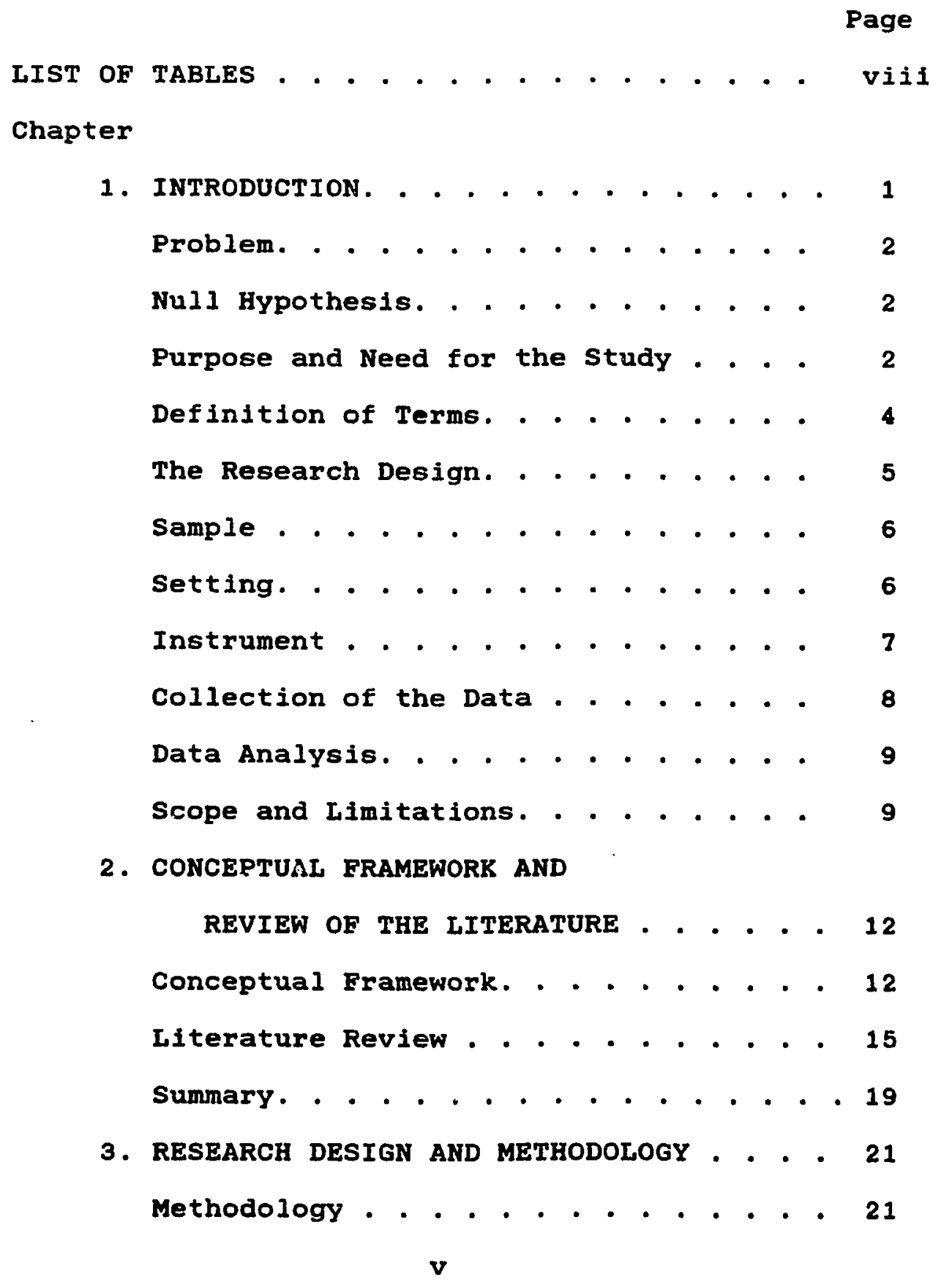


The Sample and the setting . . . . . . 22

Permission for the study . . . . . . 23

Instrument . . . . . . . . . . . . . 24

The Pilot study. . . . . . . . . . . . 24

The Instrument . . . . . . . . . . . 26

Data Collection Process. . . . . . . 28

Statistical Analysis... . . . . . . 31

Scope and Limitations. . . . . . . . . 31

4. DATA ANALYSIS AND INTERPRETATION . . . . 34

Demographic data . . . . . . . . . . 34

Analysis of Pretest Scores. . . . . . 38

Analysis of the Self-Instruction Tests. . 39

Analysis of Classroom Instruction Tests. 40

Analysis of Posttest Scores...... 40

5. CONCLUSIONS, IMPLICATIONS AND RECOMMENDATIONS

Conclusions. . . . . . . . . . . . . 43

Implications . . . . . . . . . . . . . 45

Recommendations. . . . . . . . . . 46

Summary. . . . . . . . . . . . . . . 47

REFERENCES . . . . . . . . . . . . . . . . . . 49 


Chapter
APPENDIXES . . . . . . . . . . . . . . . . . .

vi1 


\section{LIST OF TABLES}

Table

Page

1. Instrument Score Data with

Reliability Coefficients. . . . . . . 27

2. Correlation of Affect

with Multi... . . . . . . . . . 27

3. Demographic Data for

Groups $1 \& 2$ \& . . . . . . . . . . 35

4. Levels of Education and

Months of Nursing Experience. . . . . 37

5. t Tests, Pre and Posttests for

Self-Instruction and

Classroom Instruction . . . . . . . . 40

6. Likert Item Response Percentages . . . . . 43 
Chapter 1

\section{INTRODUCTION}

Professional growth of the staff nurse is an area of great concern for the nursing education department in many hospitals. Providing continuing education programs to staff nurses which are convenient and cost-effective is one of the greatest challenges facing the staff development educator today. The challenge is a result of the multitude of factors impacting on the approach the educator must take in order to provide realistic educational opportunities (Keeling, 1978).

Factors impacting on the educational growth of the registered nurse include the ever increasing acuity of the patient population. There exists an expanding body of knowledge the nurse must possess in order to maintain competency in caring for this patient population.

A second factor to consider is that state boards of nursing in many states emphasize continuing education for license renewal. Also, the Joint Commission on Accreditation of Hospitals (JCAH) has set standard educational requirements in the areas of fire and electrical safety, infection control, and cardiopulmonary resuscitation to name a few of these requirements (JCAH 
Manual, 1986). Therefore, strategies must be designed to provide the necessary education to nurses who are on the job in order to meet the requirements and to ensure current knowledge.

Problem

Because there is limited time during the working day to educate nurses, flexibility and individual instruction are necessary components of an instructional program. Programmed Instruction offers these components. Therefore, this study was done to determine if programmed instruction is an approprlate method of instruction for teaching content in the affective domain.

The problem statement is: Does programmed instruction provide nurses with a desired affective clinical competency as evidenced by their posttest scores after instruction in sexual counseling of the patient following myocardial infarction?

\section{Null Hypothesis}

Staff nurses who used programmed instruction to learn content in the affective domain will have comparable scores on a posttest when compared to students who recelve traditional classroom instruction on the topic, sexual counseling of patients following myocardial infarction. Purpose and Need for the Study Traditional classroom instruction often does not 
provide enough flexibility to meet with the schedules of on-the-fob nurse learners. It has become necessary to develop a flexible format to meet the needs of the learners while taking into consideration his or her assigned patient load, working hours, and unanticipated patient-care emergencies. The ideal learning program should be readily accessible in the work place, available whenever the employee's workload permits, and be of limited duration (Brooks, 1985).

The traditional method of providing nurses with educational programs has been in structured classroom settings. However, this method has ralsed some pertinent questions. Is this traditional approach the most costeffective method, and is there an emphasis on the active self-directed role of the adult learner (Brooks, 1985)? Self-instruction, with the use of programmed instruction, will enable the learner to participate in an educational experience at a time he/she finds most appropriate and convenient. In addition to being able to provide the staff nurse with a flexible format of instruction, the nurse educator is also concerned with the clinical competencies achlevable through the use of programmed instruction. Questions to be considered are: What type of content is appropriate for programmed instruction? Are there certain types of content which are 
inappropriate for programmed instruction?

The purpose of this study was to compare the relative effectiveness of two different methods of instruction, programmed instruction and traditional classroom instruction, on the development of skill mastery on an affective level.

\section{Definition of Terms}

For clarity, both conceptual and operational definitions are used in this study. They are as follows:

\section{Conceptual Definitions}

1. Programmed instruction was a self-paced method of learning containing behaviosal learning objectives, content, bibliography and posttests (Hanse11, 1980).

2. Traditional classroom instruction was a fifty minute lecture addressing the same objectives as the programmed instruction. Classroom instruction was evaluated using the same posttesic taken by the participants receiving programmed instruction.

3. Affective domain was learning which contains behaviors and objectives which have some emotional overtones. It encompasses likes and dislikes, attitudes, values, and beliefs (Gronlund, 1985).

4. Clinical competency was the desired behavior which was achieved as a direct result of learning that occurred following the completion of programmed 
instruction and classroom instruction.

5. Staff nurse participants in this study consisted of two groups of new graduate nurses who were employed in a critical care nurse internship program.

\section{Operational Definitions}

1. Programmed instruction for the purpose of this study consisted of objectives from the affective domain on the sexual counseling of patients following myocaraial infarction (Cohen, 1986).

2. Traditional classroom instruction was a fifty minute lecture covering the same content as the programmed instruction.

3. Affective domain objectives for the purpose of this study dealt with the attitudes and beliefs of staff nurses related to the sexual counseling of patients following a myocardial infarction.

4. Clinical competency in this study was evaluated using the posttest provided with the programmed instruction unit. The author of this study has added several attitudinal statements to be rated on a Iikert scale by the participants as part of the posttest evaluation.

The Research Design

In this study, the independent variable was the method of instruction. The dependent variable was the 
affective level of content. The study compared the effectiveness of two different methods of instruction on affective skill mastery. Instruction was provided by either (a) traditional classroom instruction or (b) programmed instruction. A pretest was administered to both groups followed by a posttest upon completion of instruction. The same test was used for the pre and posttest for both the control and experimental groups.

\section{Sample}

The subjects for this study consisted of a convenience sample of newly employed critical care nurses. The first group of nurses to participate did so in early May of 1988 and consisted of ten nurse interns who were near completion of a six month internship. The second group to participate did so at the beginning of June 1988 and consisted of ten nurses who were enrolled in a critical care orientation class. Participation in the study was on a voluntary basis. The nurses were given the option of a one hour study perlod if they chose not to participate. All prospective nurse subjects did participate in the study.

setting

The setting for the study was a staff development department at a general hospital in Southeastern Virginia. This 700-bed, JCAH approved facility had eight critical 
care areas which consisted of six intensive care units and two stepdown units. One of the stepdown units was a cardiac unit; the other was a general unit.

Instrument

The research instrument (Appendix A) consisted of fifteen multiple choice questions developed to accompany the published programmed instruction unit and six attitudinal statements written by the researcher which were rated on a Likert scale. The 23 items on the test (which were used as both the pre and posttest) were based on the behavioral objectives of the programmed instruction unit. The multiple choice questions were developed by Gretchen Hesse, of Health Education International, Inc., and accepted by Judith Cohen (1986) to be used with her article, "The Sexual Counseling of Patients Following Myocardial Infarction." The questions had not been used with any group prior to publication in Critical care Nurse. The 23 item test took approximately 20 minutes to complete.

Validity and reliability studies were conducted during the pilot phase of the present research project. The questions were presented to a panel of experts who were asked to evaluate them for content validity. The panel of experts consisted of two clinical nurse specialists, a coronary care head nurse, and a critical 
care nurse educator. The experts were asked to rate the guestions on how relevant they yere to the behavioral objectives. Only those questions rated as relevant or very relevant were retained for the final test.

Reliability of the test was determined during the pilot study by testing the internal consistency using the Kuder-Richardson-20 formula. Stability of the test was determined during the pilot period utilizing test-retest methodology. The researcher administered the test to 10 medical-surgical nurses during the pllot study. The test was refined based on the results of the pilot testing. Collection of the Data

Permission to conduct the research was collected from the staff development coordinator (Appendix B) before research began. The research proposal was submitted to the Institutional Review Board at old Dominion University before the research was conducted. The research proposal was also submitted to the Institutional Review Board at San Jose State University (Appendix C) because the researcher moved to California and completed data analysis at SJSU.

The staff nurses involved in the study were employed in a critical care nurse internship program. The researcher gave the participants a description of the study and answered any questions. Following a discussion 
of risks and benefits, each participant was provided with a copy of the Informed consent letter (Appendix D). The participants were then instructed to complete a demographic data sheet (Appendix E).

During a one hour traditional classroom instruction period, the control group was given a lecture on the sexual counseling of patients following myocardial infarction. The second group of participants received instruction on the same topic by programmed instruction. Both groups of participants were given a pretest prior to instruction and posttest upon completion.

Data Analysis

The researcher compared the pre and posttest scores of the two groups of nurses on an affective level of content. The instrument used in the study produced a raw score and therefore allowed for the use of a parametric test. A t test for independent groups was used to test for group differences on both the pretests and posttests. A .05 level of significance was used in the interpretation of the data analysis.

Scope and Limitations

The scope of this study was to determine if programmed instruction is an appropriate method of instruction for teaching content in the affective domain. A review of the literature revealed studies which dealt 
with similar comparisons but with only cognitive content. This is the first study to make a comparison between programmed instruction and traditional classroom instruction on affective content.

\section{Sample Limitations}

The staff nurses who volunteered for this study were nurses enrolled in a six month nurse internship program in critical care nursing. All of the nurses were new graduates or nurses with less than one year of nursing experience and no critical care experience. Due to the small sample size, this study cannot be generalized to the population from which it was drawn.

\section{Measurement Limitation}

The affective content being measured in this study addresses the sexual counseling of patients following myocardial infarction. The content is related to viewing the patient holistically and not just focusing on the physiologic abnormalities, as many critical care nurses do. The group of new graduate nurses who participated in this study could have been sensitized to this concept of holism in their undergraduate nursing program. Therefore, they could have entered into this instructional situation already holding the values and beliefs about sexual counseling that the researcher was trying to change as a result of the instruction. Because of this limitation, it 
would be difficult to say that programmed instruction would or would not be appropriate for other kinds of affective content.

Another limitation may be due to the lack of similar studies which used affective content in the comparison of programmed instruction with that of traditional classroom instruction. Because there were no studies, the researcher was not able to use other studies to make comparisons or inferences. Despite the identified limitations of this study, the researcher did not feel they were significant enough to make any substantial alterations in the present study. 
Chapter 2

CONCEPTUAL FRAMEWORK AND REVIEW

OF RELATED LITERATURE

This study used two educational theories for a framework. The two theories are adult learning theory and behavioristic-eclectic psychology.

Theorles of learning have been studied by theorists like Edward Lindman since the mid 1920's. One of the more modern theorists of adult learning theory is Malcolm Knowles (1978) who, in his book The Adult Learner: A Neglected Species, has cited Lindman's identification of the key assumptions about adult learners. Adults are motivated to learn if it fulfills their needs. Adult learning is life-centered; therefore, learning must be realistic and applicable to real life situations. It must be understood by the educator that adults enter into the learning situation with a lifetime of experiences which should be utilized during the learning process. Adult learners are self-directed; therefore, the role of the educator will be that of facilitator of learning rather than a director of learning.

Malcolm knowles (1978) first used the term androgogy in the mid $1960^{\prime} \mathrm{s}$. He Identified that the adult learner possesses distinct and different learning needs than those 
of a child. Until this time, pedagogy (literally meaning the art and science of teaching children) was the only existing theoretical framework for all levels of education.

One major assumption of Knowles' (1978) adult learning theory is the role of experience. This assumption is that as a person matures, he accumulates an expanding reservoir of experience that causes him to become an increasingly rich resource for learning. The next assumption, the readiness to learn, states that as an individual matures, his readiness to learn is decreasingly the product of $\mathrm{his}$ biological development and increasingly the product of the developmental tasks required for the performance of his evolving social roles. The last assumption, orientation to learning, states that children have been conditioned to have subject-centered orientation to most learning, whereas adults tend to have a problemcentered orientation to learning (Knowles, 1978).

The participants in this study are nurses who enter into this learning situation with a well-developed background of experience. Their readiness to learn results from the need to acquire the knowledge and tasks to fulfill their roles as nurses. Self-study and the use of a self-study module is a strategy for individualized instruction. According to de Tornyay \& Thompson (1987), a 
self-study module is a self-contained instructional unit that focuses on a single concept or topic and has a few well defined objectives (p. 208). The traditional method of classroom instruction is by a lecture format. According to de Tornyay \& Thompson (1987), a lecture is one in which the lecturer does all of the talking. It is organized for the participants, and decisions are made in advance of the presentation (p.96).

A second theory used in this study is Gagne's behavioristic-eclectic psychology. Bigge (1976) quotes Gagne as saying, "Learning is a change in human disposition or capability, which can be retained, and which is not simply ascribable $t:$ the process of growth. People do not learn in a general sense, but always in the sense of a change of behaviors that can be described in terms of an observable type of human performance" (Bigge, 1976, p. 179). The learning may be an increased capability for some type of performance. But, it also may be an altered disposition of the sort called "attitude," "interest," or "value" (Bigge, 1976, p. 179). Gagne's theory includes the concept of learning hierarchies to describe the internal conditions of learning. These hierarchies take the form of capabilities that are to be learned and other capabilities that are prerequisite to these. Each hierarchy consists of a set of 
intellectual skills in an order subordinate to one another (Bigge 1976;. The individual learns simpler things first, as in the cognitive domain, before being able to move on to the higher order skilis, as in the affective domain. Gagne has stressed the importance of the student being allowed to master lower order skills before the learning of higher order skills are undertaken. The focus of this research will be to determine whether affective level skill mastery can be gained through self-study as compared to traditional classroom instruction.

\section{Literature Review}

Several alternative methods of instruction are widely discussed in the literature as a means of providing professional staff education for nurses. One of them is the self-study module which contains a list of resources, directions, and/or alternatives that the learner may undertake to meet the objectives of the package. This type of module requires the participant to be very selfdirected. The individual must decide which resources will provide the information needed to meet the objectives. The self-instzuctional modules on the other hand are designed for independent use and include well defined objectives, pre and posttests, directions and materials for completion (Sherer \& Thompson, 1978). Th1s type of module will provide the learner with all the materials 
necessary to complete the objectives. One of the materials included may be that of a programmed instruction unit.

The literature search revealed several studies involving the comparison of traditional classroom instruction with self-instruction. Five studies will be discussed.

Rufo (1985) studied the effectiveness of selfinstructional packages in staff development activities. She used self-instructional packages and programmed instructional packages on cardiovascular and respiratory patient problems and tested them for their effectiveness with a group of registered nurses who were newly employed and entering critical care. The experimental group of nurses reviewed the self-instructional packages while the control group received traditional classroom instruction. Following instruction, the posttests were compared for percent correct. The results of the study revealed statistically significant differences in test results at the $\mathrm{p}<.05$ level. Overall, the experimental group performed better on the posttests than did the control group. The results suggest that the learning which took place between the two groups was greater in the experimental group. This study supports the idea that nurses can learn as effectively, if not more effectively, from programmed instruction as from traditional classroom 
instruction.

Hansell and Foster (1980) evaluated the use of

seventeen different programmed instruction modules (PIM) to that of a structured classroom teaching program for a critical care orientation. Participants in both groups were given a critical care examination prior to instruction. Scores on the examination were similar for the control and PIM groups. However, on the posttests, the PIM group scored consistently higher and had a greater mean change in score than the control group. The differences in scores were not significant at the $p<.05$ level.

Guimei (1977) conducted research to compare the effectiveness of three types of instruction on oral contraceptives: (a) programmed instruction module (PIM), (b) lecture-discussion method (LD), and (C) regular classroom instruction. The effectiveness was determined by gains in knowledge regarding the topic. The first comparison was conducted between the mean scores of the PI module and the lecture-discussion method. The $\underline{t}$ test was not significant. The next set of comparisons were made between the weighted average of the means of the PIM method and the lecture-discussion method to the means of the regular classroom instruction. This $\underline{t}$ test was significant at the $\mathrm{p}<.01$ level. The PIM and the ID 
methods were more effective in improving students performance on the posttest than the regular classroom instruction group.

Keeling and Norlega (1978) conducted a comparison study involving self-study modules. This study did not compare outcomes which measured gains in knowledge, but rather it evaluated the nurses' response to selfinstruction in cardiovascular nursing. The purpose of the study was to determine whether or not the independent study module was an effective learning method for practicing nurses in the hospltal setting. This study was conducted over a six-month period. At the completion of the study, the responses of the nurses to self-instruction were evaluated. The results revealed that independent study modules provide an appropriate, specific and practical approach to encourage professional development of the practicing nurses in a medical center (Keeling a Noriega, 1978).

Huckabay (1980) conducted a study to compare the effects of modularized instruction and traditional teaching techniques on cognitive learning and affective behaviors of graduate students. The sample consisted of graduate nursing students enrolled in an education course. Three different types of teaching strategles were used, they included: lecture discussion (LD), module (M), and 
mixed modular and lecture discussion (MLD). The students were both pre and post-tested using an objective cognitive test and a subjective cognitive test.

The first hypothesis proposed that the students who were enrolled in the mixed modular lecture-discussion group would demonstrate a significant increase in cognitive learning when measured against students in both the module or the lecture discussion group on both the objective and subjective tests. A one-way analysis of variance revealed significant differences in cognitive learning between the groups when measured on the objective test $(\mathrm{p}<.00001)$ but not with the subjective test $(\mathrm{p}<.21)$. Therefore, the hypothesis was only partially supported.

\section{SUMMARY}

The use of self-instruction and programmed instruction has been found to have several benefits. Reported advantages include greater gains in knowledge by the learner, cost-effectiveness, flexibility for the learner, placement of responsibility for achieving educational goals on the learner, and overall learner satisfaction.

All studies found in the literature review have compared self-instruction with either a lecture-discussion method of instruction or traditional classroom instruction 
to gain knowledge of cognitive content. This study differs from the above studies in that it will make a comparison between self-study and traditional classroom instruction to gain a clinical competency on an affective level. 
Chapter 3

RESEARCH DESIGN AND METHODOLOGY

This study used a comparative design to demonstrate the effectiveness of two different methods of instruction on affective skill mastery. It sought to answer the question, "Does programmed instruction provide nurses with a desired affective clinical competency as evidenced by their scores on a test covering content about sexual counseling of patients following myocardial infarction?" The independent variable was the method of instruction.

A pretest and posttest comparative design was used to study the effectiveness of two different methods of instruction on affective skill mastery. Instruction was provided (a) by traditional classroom instruction and (b) by programmed instruction. A pretest was administered to both groups followed by a posttest after completion of instruction. The pre and posttests were 1dentical tests. Methodology

The sample for this study were newly employed critical care nurses. The hospital was a 700 bed JCAH approved facility in southeastern virginia. Permission for this study was granted by the education coordinator of the education department at the hospital. The proposal for this study was reviewed and approved by the Institutional 
Review Board (IRB) at old Dominion University in Norfolk, Virginia and again by the IRB at San Jose state University. Instrument testing was completed during a pilot study which included rellability and validity testing. Data for this study were collected from two groups of nurses recelving instruction by two different methods. Each group of nurses signed a participant consent form prior to instruction. One group received instruction by traditional classroom methods while the second group received instruction by a self instruction module. A ttest was used with an alpha level of .05 for the data analysis to compare the group means of the pre and posticess of the two groups.

The Sample and the setting

The sample for this study consisted of two groups of nurses newly employed at a hospital in southeast virginia. The newly employed nurses had been hired into the critical care setting. The sampling for the study was nonprobability and convenient.

The first group of nurses to participate in the study did so in May. This group of nirses was enrolled in a six month internship program in critical care and was near the end of the program.

The second group of nurses to participate in the study consisted of ten newly hired medical-surgical nurses 
who were enrolled in a two week critical care orientation class. This second group of nurses participated in the study in June.

The setting for this study was the staff development department at a general hospital in southeastern Virginia. This 700-bed JCAH approved facllity had elght critical care areas which consisted of six intensive care units and two stepdown units. One of the stepdown units was a cardiac unit and the other was a general stepdown unit.

$$
\text { Permission for the study }
$$

In March of 1988, the researcher submitted a proposal to the Human Subjects Review at old Dominion University in Norfolk, Virginla. Permission was requested to conduct a pretest and posttest comparative analysis to determine if there was a difference in an affective skill mastery of students who received instruction by traditional classroom instruction and those students who were self-instructed. The proposal was reviewed and approved (Appendix C). A site approval request, necessary to conduct the research study, was submitted to the education coordinator at the facility where the research was to be conducted. Along with the site approval request, a copy of the research proposal was included for review. The site approval request briefly described the involvement of the participants, explained how confidentiality of the 
students was to be protected and guaranteed that the hospital would not be identified by name in any of the writings related to the research study. Site permission for the study was recelved (Appendix B). Permission was then obtained from the Institutional Review Board at San Jose State University to use the data collected in virginia.

\section{Instrument}

The necessary data for this study were acquired using a 23 item test (Appendix A). The test consisted of fifteen multiple choice items and eight attitudinal statements whlch were rated on a Likert scale. A pilot study was done prior to this study.

The Pilot study

In March of 1988 a pilot study was conducted to gather data about the reliability and stability of the instrument (Appendix A) being used for the study. During the pilot study, the instrument was distributed to a panel of clintcal experts who were asked to evaluate it for content validity. These experts consisted of two critical care clinical nurse specialists. Of the two clinical specialists one was a cardlovascular clinical nurse specialist and the other was a general critical care clinical specialist. The other two experts consisted of a coronary care head nurse and a critical care nurse 
educator.

The experts were asked to rate the items on how relevant they were to the behavioral objectives. The rating was done on a likert scale with choices of very relevant, relevant, slightly relevant, and not relevant. only those questions rated as relevant and very relevant were retained. All questions on the instrument were rated as relevant or very relevant by the clinical experts.

Ten critical care nurses working on one of the stepdown units were then asked to participate in the pilot study. All participation in the pllot study was done on a voluntary basis. Each staff nurse was administered the 23 item instrument on the unit; the instrument was administered again two weeks later. Reliability of the instrument was determined by testing for internal consistency using the Kuder-Richardson-20 formula.

The AFFECT items were attitudinal statements which the participant was asked to rate on a Likert scale. The scale was rated 1 - 5, strongly disagree to strongly agree respectively. It was possible for each participant to rate the statement from one to five. The actual range of scores was 1.2 to 4.2 with $a$ mean of 1.8 and a standard deviation of .99. The item alpha was particularly low at .36 (Table 1). There was very little variance between the answers from all participants. 
The MULTI items were multiple choice questions which were scored as either correct or incorrect, 0 = incorrect while 1 = correct. For each item the possible range of scores was $0-1$, while the actual range of scores was . 30 to .90 with a mean of .66 and a standard deviation of .05 . The item alpha was .32 (Table 1). Seven of the MuLTI items showed no variance.

The correlation matrix computed for the data revealed a Pearson correlation of .52 which was not significant at alpha level of .05. (Table 2). This correlation shows a 27 percent overlap in the variation between the AFrECT items and the MULTI 1tems. It is suspected that the correlation would have been. higher if there had been more variation between the MULTI items.

\section{The Instrument}

The research instrument (Appendix A, Posttest for Sexual Counseling of the Patient Following Myocardial Infarction) consisted of 15 multiple choice questions developed to accompany a published self-instructional unit and 8 attitudinal statements written by the researcher which were rated on a likert scale.

The attitudinal statements were designed to explore the nurses values and opinions related to the topic of sexual counseling of patients following myocardial infarction. The twenty three items on the test (which were 
Table 1

Instrument Score Data with Reliability Coefficients

\begin{tabular}{lccccc}
\hline Instrument & $\begin{array}{l}\text { Possible } \\
\text { Range }\end{array}$ & $\begin{array}{l}\text { Actual } \\
\text { Range }\end{array}$ & M & S.D. & Alpha \\
\hline AFFECT & $1-5$ & $1.2-4.2$ & 1.80 & .99 & .36 \\
MULTI & $0-1$ & $0.3-0.9$ & .66 & .05 & .32 \\
\hline
\end{tabular}

Table 2

Correlation of AFEECT with MULTI

\begin{tabular}{lll}
\hline & $r$ & $p$ \\
AFFECT with MULTI & .52 & .06 \\
\hline
\end{tabular}


used as both the pretest and the posttest) were based on the behavioral objectives of the self-instructional unit. The multiple choice questions were developed by Gretchen Hesse of liealth Education International, Inc., and used by Judith Cohen in her article on "The Sexual Counseling of Patients Following Myocardial Infarction." The questions had not been used with any group prior to publication in Critical Care Nurse. Validity and reliability studies had not been conducted on this test. For the purpose of this study, a pilot study was done to explore the reliability and validity of the instrument. The alloted time to complete the instrument was 30 minutes.

\section{Data Collection Process}

During a one hour traditional classroom instruction period, the control group was given a lecture on sexual counseling of the patient following myocardial infarction. Prior to instruction the group was given a pretest. The participants were provided with behavioral objectives (Appendix F) at the beginning of the lecture. Following the completion of the lecture, the participants took a supervised posttest on the lecture content. The experimental group was provided with a one hour study period to complete the self-instructional unit. The nurses who studied the self-instructional unit took the same supervised posttest as did the control group. 
The first group of nurses participated in the study in May of 1988 while the second group participated in June of 1988. The liklihood of contact by the two groups had been minimized by using the first group in May and the second group in June. While the June group was in class, the May group was already working on the units.

\section{Consent Forms}

A participant consent form (Appendix D) was administered to each participant at the beginning of each instructional period. The researcher was present to answer any questions regarding the study. An explanation of the risk-benefit ratio was given to the participants by the researcher. The benefits of the study were described as assisting in the collection of data which will be used by staff development educators to make decisions regarding approaches to teaching varlous levels of skill. The only risk identified by the researcher was the possible discomfort experienced by each participant associated with an assessment of his/her level of knowledge related to the topic of sexual counseling of patients following myocardial infarction. None of the participants at any time expresed any discomfort regarding an assessment of their knowledge level in this area.

All participants were assured that they would be able to withdraw from the study at any time without any effects 
on their work or classroom evaluations. Confidentiality of score results was assured for each participant. At the time of testing, it was not necessary for the participants to identify themselves on the tests. The pre and posttesto were number coded when they were given to the participants. All participants were assured that only the researcher would score the tests. After the participants read the informed consent, they signed the forms on the back page. Some participants included their addresses so they could receive results of the study once the study was completed.

After the informed consent forms were collected, the students were asked to complete a demographic data sheet (Appendix E). The demographic data sheet requested information regarding age, gender, marital status, ethnicity, nursing education (first and highest levels). years of experience in nursing as well as years of experience in critical care nursing. The demographic data sheet also asked whether or not the participant had ever been involved in sexual counseling of patients following myocardial infarction or if they had ever received education in that area prior to this study. Administration of the Instrument

After the consent forms and dewographic data sheets were completed, all participants were given verbal 
instructions (as well as written instructions on the test) on how to complete the written pretest. Each test was coded with a number 1 to 10 .

Following each method of instruction the participants were given a posttest to complete. Both the pretests and the posttests were scored by the researcher. The multiple choice questions were compared for percent correct between the two groups. The attitudinal statements were ccmpared for a change in reported attitudes and beliefs before instruction and following instruction.

\section{Statistical Analysis}

The instrument used in this study consisted of 15 multiple choice questions and 8 attitudinal statements. The multiple choice questions were compared for percent correct between and within the two groups. The researcher compared the pre and posttest scores of the two groups of nurses on an affective level of content. The instrument used in this study produced a raw score on the 15 MULTI items ; therefore, a parametric test was used. A $\underline{t}$ test for independent groups was used to test group differences. The .05 level of significance was used in the interpretation of the data.

Scope and Limitations

A review of the literature revealed several studies which compared classroom instruction with self-instruction 
(through the use of self-learning packages and programmed instruction) to achieve mastery of cognitive content. A comparison between classroom instruction and selfinstruction to achieve an affective clinical competency had not been investigated until the present study. As a result, no comparisons could be made or inferred based on previous studies.

\section{Sample Iimitations}

The nurses who volunteered for this study were two groups of newly employed critical care nurses. Each group consisted of 10 participants. All of the participants were female, therefore the results of the study may not be representative of the male nurse population. Also, due to the small sample size, this study cannot be generalized to the broader population of critical care nurses.

Another possible limitation was the differences in the nurses level of education. Nurses who were baccalaureate prepared were not as well represented. The mean age of the first group of nurses was younger than the second group. The second group also had several more years of nursing experience than the first group.

\section{Measurement Limitations}

The instrument used for pretesting and posttesting the participants had not been used prior to publication in Critical Care Nurse. There were no reliability or validity 
studies available on the instrument. The pilot study, which was conducted to provide validity and reliability data on the instrument, was carried out on a small group of 10 medical-surgical nurses. Several of the questions on the test revealed little or no variance in the responses. All multiple choice questions were retained on the instrument because they were being used with the article which accompanied the test as a published unit. Even though these limitations were noted, steps to reduce the varlability were instituted, particularly in the pilot study. 


\section{Chapter 4 \\ DATA ANALYSIS AND INTERPRETATION}

Data from this study were analyzed to determine if there was a difference in the scores between two groups of nurses instructed by two different teaching methods. One group was instructed using traditional classroom techniques and the other group was instructed using techniques of self-instruction. Analysis and interpretation accompanies each group of data in this chapter.

\section{Demographic Data}

The data summarized in this section were collected on the demographic data form which each participant completed at the beginning of each instructional session. Table 3 displays the demographic profile of the participants in Group 1 and in Group 2. These data showed the following: The first group of nurses consisted of 10 females, ranging in age from 24 - 28 years. Six participants were single, three marrled, and one separated. Four participants held baccalaureate degrees in nursing, four held a diploma in nursing, and two held associate degrees in nursing. The second group also consisted of 10 females, ranging in age from $25-43$ years. Five of the participants were single, three married, and two 
Table 3

Demographic Data for Groups $1 \& 2 \quad(N=20)$

\begin{tabular}{lrr}
\hline Characteristic & $G-1$ & $G-2$ \\
\hline SEX & $(n=10)$ & $(n=10)$ \\
Male & 0 & 0 \\
Female & 10 & 10
\end{tabular}

Marital status

$\begin{array}{lll}\text { Married } & 7 & 2 \\ \text { Single } & 2 & 6 \\ \text { Separated } & 1 & 2\end{array}$

Ethnicity

$\begin{array}{lll}\text { Black } & 2 & 0 \\ \text { Hispanic } & 0 & 2 \\ \text { Caucasian } & 8 & 8\end{array}$


separated. Five of the participants in the second group held a diploma in nursing and five held an associate degree in nursing. Eighty percent of all participants in both groups were caucasian, while $20 \%$ were either black or hispanic.

\section{Level of Education}

Table 4 displays the level of education and the number of months of nursing experience for each participant. The data were separated into Groups 1 and 2 on the table. Levels of education were divided into two categories: (a) first level of nursing education and (b) highest level of nursing education. Nursing experience was divided into (a) months of nursing experience and (b) months of nursing experience in critical care.

The typical participant in Group 1 had either a diploma or a baccalaureate degree as his/her highest level of nursing education. The same was also true for the first level of education for 9 participants, with the exception of one nurse whose first level of education was licensed practical nurse education. The average months of nursing experience in Group 1 was 16 months. The average months of nursing experience in critical care for this group was 5.3 months. This first group of nurses to participate in the study were enrolled in a critical care internship program. All nurses in Group 1 were new graduates from nursing 
Table 4

Levels of Education and Months of Nursing Experience $(N=20)$

Characteristic

G-1

G-2

First level of

nursing education

Diploma

Associates

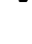

Bacalaureate

IPN

$(n=10)$

$(n=10)$

$$
\text { nu }
$$

Associates
Bacalaureate
IPN

Highest level of nursing education

Diploma

Associates

Bacalaureate

Months of

nursing experience

Range

5-e 5

$24-186$

Mean

16.70

85.45

Months of nursing

experience in

critical care

Range

$5-8$

$0-7$

Mean

5.30

16.70 
school except two.

In Group 2, 60\% of the participants had an associate degree in nursing and $40 \%$ had a diploma in nursing as his/her first level of nursing education. The same was true for the highest level of education for all participants in Group 2. The mean number of months of nursing experience in Group 2 was 85 months. The mean number of months of nursing experience in critical care nursing for this group was 16.7 months. The nurses in Group 2 were enrolled in a critical care orientation course. It is possible that within this group there were nurses who had worked in critical care in another institution.

According to the demographic data sheet, none of the participants had received any education related to the sexual counseling of patients following myocardial infarction, nor had they ever been involved in the actual counseling of patients in this area prior to participation in this study.

Analysis of Pretest Scores on the MULTI Items The pretest scores on the MULTI items for the self instruction group and the classroom instruction group were calculated using a $t$ test. Because the groups differed in their years of nursing experience and months of critical care nursing experience, it was useful to know how the two 
groups performed comparatively on the pretests.

There were 15 MULTI items which were compared. The mean score for the classroom instruction group was 11.9 on the pretest and 14.2 on the posttest. In the programmed instruction group the mean pretest score was 12.1 and the mean posttest score was 14.4. Analysis of the pretest scores revealed that there was a statistically significant difference at the .05 level in the pretest scores between the classroom instruction group and the self-instruction group $(\underline{t}(18)=1,35, \underline{p}=.025)$ (Table 5). The fact that the two groups differed in the number of years of nursing experience could explain the statistically significant effect on the results of their pretest scores on a test of the sexual counseling of patients following myocardial infarction.

Analysis of the Self-Instruction Tests

The pretest and the posttest MULTI items for the self instruction group were also compared using a $t$ test. A significant difference in the pretest and the posttest may indicate a gain in knowledge related to the sexual counseling of patients following myocardial infarction.

Analysis of the scores for the self instruction group revealed a statistically significant difference between the pretest and the posttest scores for the selfinstruction group $(\underline{t}(9)=9.18, \underline{p}<.0001)$ (Table 5). 
Table 5

T Tests, Pre and Posttests for Self-Instruction and Classroom Instruction.

\begin{tabular}{lccc}
\hline Pairs & $t$ & d.f. & p-value \\
\hline $\begin{array}{l}\text { Self Instruction } \\
\text { Pre and Posttests }\end{array}$ & 9.18 & 9 & .0001 \\
$\begin{array}{l}\text { Classroom Instruction } \\
\text { Pre and Posttests }\end{array}$ & 6.73 & 9 & .003 \\
$\begin{array}{l}\text { Pretests, Classroom } \\
\text { and Self-Instruction }\end{array}$ & 1.35 & 18 & .025 \\
$\begin{array}{l}\text { Posttests, classroom } \\
\text { and Self-Instruction }\end{array}$ & 1.00 & 18 & .193 \\
& & & \\
\hline
\end{tabular}

The critical value of $t$ for alpha equal to .025 and 9 d.f. is 2.2 . 
In fact, the group performed better on the posttest than they did on the pretest. This suggests that the intervention of the self-learning module may have had an impact on the learning which took place between the pre and posttests.

Analysis of Classroom Instruction Tests

The pre and posttests on the MULTI items for the classroom instruction group were compared using a $t$ test. A significant difference in the pre and posttest scores would indicate a gain in knowledge related to the sexual counseling of patients following myocardial infarction.

The statistical analysis of the pretests and the posttests for the classroom instruction group revealed a statistically significant difference between the pre and posttest scores in the classroom instruction group (Table 5). This group performed better on the posttests than they did on the pretests. The same results existed for the classroom instruction group as for the self-instruction group. Both groups performed better on the posttest than they did on the pretests.

The results show that possible learning took place within both groups between the time when they took the pretest and when they took the posttest.

Anajysis of Posttest scores

The posttest scores on the MULTI items of the two 
groups, classroom instruction and self-instruction were compared for a statistical difference using a $t$ test. The null hypothesis in Chapter 1 stated that there would be no difference in the posttest scores on the sexual counseling of patients following myocardial infarction between the classroom instructed group and the self-instructed group.

According to the analysis of these two groups of scores, the calculated value of $\underline{t}=1.00$ was insignificant at the .05 level (Table 5 ). With a calculated value of $\underline{t}=$ 1.00, the null hypothesis that the classroom instruction posttests were equal to the self-instruction posttests was not rejected. Therefore, the participants in this study performed the same on a posttest whether they had received classroom instruction or self-instruction. Both groups were able to improve their posttest scores regardless of the method of instruction used.

\section{Analysis of Iikert Item Scores}

The Iikert items were compared on the pretest and the posttest for a change in attitudes about the sexual counseling of patients following myocardial infarction. The participants showed a change in attitude about the value of counseling of patients as well as the person responsible to do the counseling. On the pretest, most participants thought that it was not necessarily the nurses' responsibility to do the sexual counseling of 
patients following myocardial infarction. However, on the posttest, most participants changed their answer to reveal that it was the nurses' responsibility to do the counseling of these patients.

Table 6

Likert Item Response Percentages

\begin{tabular}{lllllllll}
\hline Item & 1 & 2 & 3 & 4 & 5 & 6 & 7 & 8 \\
\hline $\begin{array}{c}\text { Classroom Group } \\
\text { Pretest }\end{array}$ & & & & & & & & \\
SD & .2 & .1 & & .6 & .8 & & & \\
D & .4 & .4 & .2 & .3 & .2 & .2 & .3 & .2 \\
A & .4 & .5 & .5 & .1 & & .6 & .5 & .2 \\
SA & & & .3 & & & .2 & .2 & .6 \\
Posttest & & & & & & & & \\
SD & .4 & .6 & .2 & .7 & .8 & .5 & .5 & .2 \\
D & .6 & .4 & .6 & .3 & .2 & .4 & .4 & .6 \\
A & & & .2 & & & .1 & .1 & .1 \\
SA & & & & & & & & .1
\end{tabular}

Programmed Group

Pretest

$\begin{array}{rllllllll}\text { SD } & .2 & .2 & .3 & .6 & .8 & & .5 & \\ \text { D } & .3 & .3 & .4 & .4 & .2 & .3 & .4 & .1 \\ \text { A } & .5 & .5 & .3 & & & .5 & .1 & .6 \\ \text { SA } & & & & & & .2 & & .3 \\ \text { Posttest } & & & & & & & & \\ \text { SD } & .4 & .5 & .3 & .7 & .8 & .5 & .6 & .3 \\ \text { D } & .6 & .5 & .6 & .3 & .2 & .5 & .4 & .5 \\ \text { A } & & & .1 & & & & & .2 \\ \text { SA } & & & & & & & & \end{array}$

$\mathrm{SD}=$ strongly disagree, $\mathrm{D}=$ disagree, $\mathrm{A}=$ agree, $\mathrm{SA}=$ strongly agree. 


\section{Chapter 5}

CONCLUSIONS, IMPLICATIONS AND RECOMMENDATIONS

A pretest and posttest comparative design was used to determine the effects of two different methods of instruction on the topic of sexual counseling of patients following myocardial infarction. The posttests were compared using a paired $t$ test to determine if there was a statistically significant difference in the scores between the two groups. The null hypothesis being investigated was that there would be no difference in the posttest scores on the topic of sexual counseling of patients following myocardial infarction between the classroom instruction group and the self-instructed group.

The population of nurses under study was small. Also, the participants in the study were all female. The statistical analysis of the data indicated some important conclusions about the method of instruction used to teach affective content such as the sexual counseling of patients following myocardial infarction.

Conclusions

significant changes in the scores on the pretests and posttests were found in both groups. There were significant differences in scores on the pretests between the two groups, but were not any significant differences 
in the posttest scores between the two groups. These results cannot be generalized beyond the study group because of the small sample size.

\section{Pretest scores}

The differences in pretest scores between Groups 1 and 2 were found to be significant. The two groups differed in relation to the demographic data collected. The mean age of the two groups was different. More importantiy, the mean number of years of nursing experience was different. In the self-instructed group the mean number of months of nursing experience was 16.7 months, whereas the classroom instruction group had an average of 85.5 months of nursing experience. The fact that the two groups differed on the pretest scores was probably due to the difference in the number of years of nursing experience as well as the difference in the number of years of experience in critical care.

Pre and Posttests Differences

The pre and posttests of the self-instruction group and the classroom instruction group were compared for a statistically oignificant difference in scores. Both groups showed improvement from pretest to posttest scores. Both methods of instruction, self-instruction and classroom instruction, resulted in improved scores on the posttests. 


\section{Posttest Scores Differences}

The posttest scores between the self-instruction group and the classroom instruction group were found to be insignificant. Because there was no statistically significant difference in the scores between the two groups on the posttests, it may be concluded that affective content taught in this study may be effectively taught by either method of instruction.

$$
\text { Implications }
$$

This study provides the educator with valuable information regarding the effectiveness of two different methods of instruction wher teaching affective content. The findings support the fact that affective content may be successfully taught to nurses by elther classroom instruction or self-instruction. Both methods of instruction were able to provide the nurse with equal amounts of knowledge to improve her score on a posttest of affective content.

One additional finding whlch was not presented in the statistical analysis of the two methods of instruction was the discussion among the students about the class content in the classroom setting. The nurses who were instructed within the classroom setting were able to engage in discussion about the class content and offer suggestions 
to each other on how to make sexual counseling of patients an approachable topic in the clinical setting. The students in the classroom group were also able to ask many questions of the instructor and of each other during the instructional period. The self-instructed group did not engage in discussion with each other nor did they ask questions about the study content while they completed the moduje.

Although both groups showed an increase in knowledge on the posttests, the classroom instructed group experienced some unexpected benefits of being in a classroom setting. The educator should take this benefit of classroom instruction into account when deciding which method of instruction to use to teach affective content.

\section{Recommendations}

Further studies are needed to provide supportive evidence of the effectiveness of using self-instruction modules when teaching affective content. Future studies would need a larger sample size in order to generalize to the larger population of nurses. Also, the groups need to be randomized to control for the variables of experience and age. This study only compared the pre and posttest completed by both groups. A recommendation for future study on the same affective topic may be to survey nurses and actually observe the nurses ir the clinical setting 
for the occurence of sexual counseling of patients following myocardial infarction. A chart audit may even be appropriate to provide the researcher with information on the number of documented teaching episodes between nurse and patient regarding this topic. By using a combination of audits, observations and testing the following question could be answered: Is there a difference in the actual performance of sexual counseling of patients following myocardial infarction between nurses who received selfinstruction and nurses who received classroom instruction? The observation of nurses in the clinical setting by the researcher was beyond the scope of this study.

Summary

The results of this study provide the educator with pertinent information regarding the teaching of affective content by two different methods of instruction. The study demonstrated that affective content may be effectively taught to nurses by classroom instruction and by selfinstruction with no statistically significant difference in posttest scores between the two groups.

The educator who 18 considering teaching affective content by self-instruction may want to consider some of the unexpected benefits of classroom instruction discussed in this study. The classroom instructed group had an opportunity to ask questions and exchange ideas with each 
other. The self-instruction group had the benefit of engaging in an educational experience which was both flexible and self-directed. The educator will consider the above benefits of both types of instruction when deciding which type is most approprlate for the class content. 
REFERENCES

50 
References

Bigge, M. (1976). Learning theories for teachers (3rd ed. $)$, New York: Harper \& Row.

Bloom, B.S. (1956). Taxonomy of educational objectivesthe classification of educational goals handbook I: Cognitive domain, New York: David McCay Co.,Inc.

Brooks, B. (1985). Self-learning: An approach to cost effective staff development. Journal of Continuing Education in Nursing, 16(5), 165-166.

Cohen, J. (:986:. Sexual counseling of the patient following myocardial infarction. Critical Care Nurse, $\underline{Z}(6), 18-27$.

de Tornyay, R., \& Thompson, M. (1987). Strategies for teaching nursing, New York: Wiley \& Sons. Gentine, M. (1980). Methods of teaching - revisited selflearning packages. The Journal of Continuing Education in Nursing, 11(3), 57-58.

Gronlund, N. (1985). Measurement and evaluation in teaching (5th ed.), New York: MacMillan. Guimei, M. (1977). Effectiveness of a programmed instruction module on oral contraceptives. Nursing Reasearch, 26(6), 452-455.

Hansell, H., E Eoster, S. (1980). Critical care nursing orientation: A comparison of teaching methods. Heart 
\& Lung, $\underline{9}(6), 1066-1072$.

Hast, A.S. (1986). An approach to cost effectiveness education in the critical care seting. Critical Care Nurse, $\underline{I}(2), 86-89$.

Hast, A.S. (1987). Self-learning packages in critical care. Critical Care Nurse, $\underline{Z}(2), 110-116$.

Huckabay, I. M. D. (1981). The effects of modularized instruction and traditional teaching techniques on cognitive learning and affective behaviors of student nurses. Advances in Nursing Science, $3(3), 67-83$. Joint Commission on Accreditation of Hospitals. (1987). Accreditation manual for hospitals, Chicago: Author. Keeling, A., \& Noriega, I. (1978, April). Continuing education -independently. Supervisor Nurse, 45-51.

Knowles, M. (1978). The adult learner: A neglected species (2nd ed.), Houston, Tx.: Gulf.

Kruthwohl, D.R.. \& Masia, B.B. (1265). Taxonomy of educationalobjectives - the classification of educational goals handbook II : Affective domain, New York: David McKay.

Porter, S. (1977). Application of computer assisted instruction to continuing education in nursing. Journal of Continuing Education in Nursing, $9(6), 5-$ 9. 
Rufo, K. (1985). Effectiveness of self-instructional packages in staff development activities. Journal of Continuing Education in Nursing, 16(3), 80-84.

Sherer, B. K., \& Thompson, M.A. (1978). The process of developing a learning center in an acute care setting. Journal of Continuing Education in Nursing, $\underline{9}(1), 36-44$.

Swedenson, I. (1981, November). Self-instruction: Benefits and problems. Nurse Educator, 6-9. 
APPENDIX A

Pretest / Posttest

Sexual Counseling of the MI Patient 


\section{PLEASE NOTE:}

Copyrighted materials in this document have not been filmed at the request of the author. They are available for consultation, however, in the author's university library.

These consist of pages:

55-59,

Sexual Counseling of the HI Patient

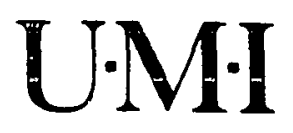


APPENDIX B

Site Permission Letter

60 
Sample Letter: Site Approval Request

Education Coordinator:

I am a graduate student enrolled in the masters program at Old Dominion University School of Nursing. To partially fulfill the requirements for my degree, I am conducting research on the comparison of programmed instruction with that of traditional classroom instruction to achieve a selected clinical competency in staff nurses.

The participants of the study will include those nurses who are enrolled in the critical care orientation class and the critical care nurse interns. The participants will take a pretest on "Sexual Counseling of Patients Following Myocardial Infarction". One group will be given a self-instructional programmed instruction unit. while a second group will be given traditional classroom instruction. Following instruction, both groups will be given a posttest.

The pre and posttest scores will be viewed by the researer, thereby protecting the confidentiality of each participant. The hospital will not be identified by name in any of the writings related to the research study.

The research proposal and a copy of the instrument is enclosed for you to review. I will be available to answer any questions you may have regarding the research study. I can be reached in the Staff Development Department at ext. 3409 . 
Thank you for your consideration in this matter.

Sincerely,

Laurie Laverty RN, CCRN Graduate Nursing Student old Dominion University 
APFENDIX C

Institutional Review Board

Permission 


\section{C.JSL FOUL:DETIOH \\ HUMAN SUBJECTS INSTITUTIONAL REVIEW BOARD PROJECT PROPOSAL REVIEW 3 Fi '}

1, the undersigned member of the San Jose State University Human Subjects institutional Review Board, have reviewed the following proposal submitted to the Committee on October 14, 1988 by:

PRINCIPAL INVESTIGATOR: Laurie J. Laverty

PROTOCOL \#: 7374

PROJECT TITLE: A COMPARISON OF AN AFFECIIVE LEVEL OF PROGRAMMED INSTRUCTION TO ACHIEVE A CLINICAL COMPETENCY IN NURSES

I recommend the following action (indicate one):

1. Approved for clearance as involving minimal risk to Human Subjects.

2. Approved for clearance with risk to Human Subjects.

3. Approved for clearance when the following conditions are met:

4. Not Approved (return to principal investigator for following reasons):

5. Expedited Review (specify condition[s] that merit expedited review):$$
\text { 3. Approved tor clearance when the tollowing conditions are met: }
$$

sons):

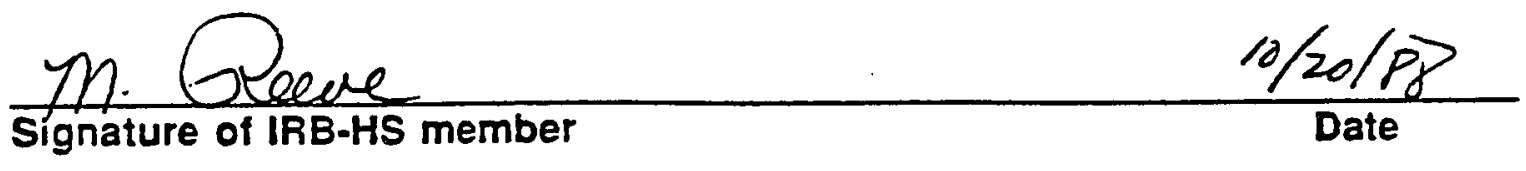

OFFICIAL SIGAING FOR INSTITUTION

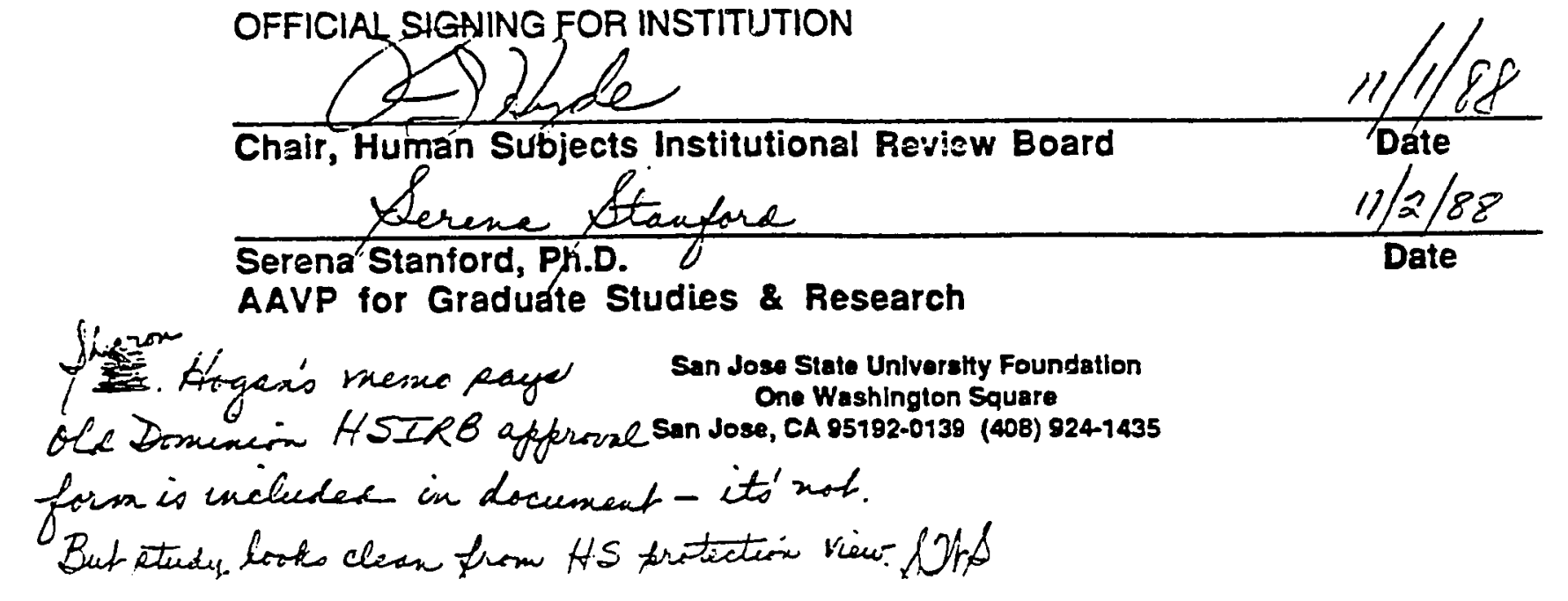


APPENDIX D

Participant Informed Consent 
Dear Potential Participant:

I am a graduate student enrolled in the masters program at old Dominion University School of Nursing. To partially fulfill the requirements for graduation, I am conducting research on the comparison of programmed instruction with that of traditional classroom instruction to achieve a clinical competency. Although your participation in this study will not directly benefit you, there will be a benefit provided to staff development educators regarding alternative approaches in teaching various levels of skill.

Your participation in this study will involve receiving instruction on the sexual counseling of patients following myocardial infarction, either by programmed instruction or traditional classroom instruction. You will be asked to take a pretest prior to instruction and a posttest following instruction. You will be identified only by a code number on the tests, it will not be necessary for you to indicate your name on the test. The pretest and posttest will be scored only by the researcher. The results of your individual pre and posttest scores will not be shared with your head nurse or anyone else in the hospital. Only the researcher will have access to your scores.

Your participation in this study is voluntary. You may withdraw at any time up to and during the instructional process without any effects on your work or class evaluation. 
Your agreement to participate in this study will be demonstrated by your participation infilling out the demographic data sheet, pre/posttest, and the instructional activity.

The results of the research will be available to all participants upon request. You may request the research results by including your name and address on the back of the demographic data sheet and a copy will be sent to you.

If you have any further questions, I can be reached in the Staff Development Department ai ext. 8-3409.

sincerely,

Laurie Laverty, RN, CCRN 
APPENDIX E

Demographic Data Sheet 
Demographic Data Sheet

Directions: Please answer each question by filling in the blanks
or by cheching the appropriate answer. Please DO NOT
put your narne on this form.
Thank you for your participation.

1. Age

2. Sex: Male Female

3. Marital Status:

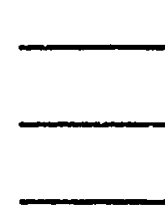
Single Divorced Married Widowed separated

4. Race: Black Hispanic Caucasian Asian Other (Specify):

5. Nursing Education:

A. FIRST level of Nursing Education achieved:

Diploma
Associate Degree
Bachelors Degree
Other (Specify):

B. HIGHEST level of Nursing Education achieved:

Diplona
Associate Degree
Bachelors Degree
Other (Specify):


6. Amount of nursing experience since graduation from initial Nursing Education (please indicate to the nearest month):

Years _ Months

7. Amount of nursing experience in critical care (indicate to the nearest month):

Years Months

8. Areas of clinical experience (please check all that apply):

\begin{tabular}{ll}
\hline Obstetrics & ICU/CCU \\
Med/Surg & Emergency Room \\
Nursery & Public Health \\
OR/RR & Clinic \\
Psychiatric & Other (Specify):
\end{tabular}

9. Have you ever been involved in the sexual counseling of a fatient following myoceraial infarction?

Yes
10. Have vou ever received ecucation related to the sexual
counseling of a patient following myocarcial infarcion?

Yes

No 


\section{APPENDIX F}

Behavioral Objectives

71 


\section{BEHAVIORAL OBJECTIVES}

Based on the content of the instruction that follows, the learner should be able to meet the following objectives:

1. Recognize a MI patient who needs sexual counseling.

2. Describe the psychologic effects of myocardial infarction that may influence sexual interest or activity.

3. Recognize the physiologic effects of sexual activity.

4. Apply knowledge of psychologic effects of sexual activity.

5. Discuss the goals of sexual counseling for a patient who has had a myocardial infarction.

6. Describe guidelines for effective sexual counseling of the MI patient. 